\title{
Subjective experience of a confusional state ${ }^{\dagger}$
}

\section{J. L. CR AMMER}

\section{Background Confusional states associated with medical and surgical conditions require more study and biochemical explanation.}

Aims To understand impairment of consciousness, cognition and memory.

\section{Method A psychiatrist reports} experience of his changing mental state over 5 days from notes made immediately on recovery.

Results Aprodromal phase of declining consciousness, understanding and memory registration over perhaps $48 \mathrm{~h}$ was difficult to detect. During unconsciousness there were four brief partial reversals with arousal, and some mental functioning (memory, formation of beliefs) occurred.

\section{Conclusions Self-reportcan be a} useful addition in clinical study, and patients with renal failure require psychological and psychiatric study. Comparison with the mental effects of benzodiazepine or of an anaesthetic such as nitrous oxide might throw light on the pathology.

\section{Declaration of interest None}

Toxic confusional states (acute brain syndromes) characterised by impaired consciousness, loss of comprehension, disorientation and misidentification in the setting of an organic illness (the recognition of which sometimes may be difficult) come in varying degrees of severity (Lishman, 1998). At one extreme is the delirious patient, with hallucinations, restlessness and emotional expressions, demanding nursing attention, medical management and perhaps psychiatric intervention. At the other extreme is a patient who is quiet, passive, even withdrawn, and whose mental state (inattentive, forgetful, misunderstanding) may pass unremarked by the nurse or disregarded by the doctoralthough such a state may make management more difficult.

Delirium tremens apart, case reports seem extremely rare (Mickle, 1901; Lipowski, 1990; Kapur, 1997) and concern reaction to infections rather than biochemical disorder as in renal failure.

I describe here my own experiences during which, while in a surgical ward, I slid into unconsciousness for 4 days (with fluctuations in depth) until revived by haemofiltration. It is based on notes I wrote shortly after recovery, while recollection was sharp, with added explanatory comment before I had read any scientific literature (Lishman, 1998).

\section{THE CASE}

A retired psychiatrist aged 79 years and weighing about $70 \mathrm{~kg}$ had suffered for a number of years from atrial fibrillation with incipient congestive cardiac failure and mild hypertension, for which he had received warfarin, furosemide and enalapril. In August 1999, following a period of nausea and anorexia with fatty stools, he saw a physician who diagnosed chronic renal failure on the basis of a chronically raised serum creatinine level and an ultrasound scan that showed atrophy of one kidney and shrinkage of the other. On oral aluminium hydroxide he remained symptom-free and he had no previous history of psychiatric illness.
On the afternoon of 23 November he had an unexplained fall down two steps, landing heavily on his right hip. Thereafter he was unable to walk or even stand because of extreme weakness and pain in the right leg. On being admitted to a local surgical ward, no fracture was demonstrated on repeated $X$-ray, no diagnosis or prognosis was given and the physiotherapist could only prescribe bed exercises.

His wife visited every morning and afternoon. In the afternoon of the third day after the fall (26 November) she noticed that he had become strange in manner, only partially attentive to her, his gaze wandering, and saying "It's very strange", not replying to her questions or just beginning "-er-" and not repeating to her what she said when she asked him to do so. She asked the nurse if he had been heavily sedated.

He was transferred to a medical ward for closer care. Serum creatinine and urea levels were raised (see Table I), acute renal failure was diagnosed and on the morning of 28 November he was transferred 25 miles by ambulance to the Intensive Treatment Unit of John Radcliffe Hospital (Oxford) for haemofiltration (an exchange of about 30 litres of plasma over about 6 h). He recovered consciousness on the afternoon of 30 November, at once recognising and speaking with his wife who was then at his bedside on one of her regular visits; she told him also that their daughter had come from London to visit on two previous days.

In view of asystolic episodes of up to $6 \mathrm{~s}$ shown on a 24-h electrocardiogram, he was fitted with a permanent transvenous ventricular cardiac pacemaker.

\section{THE EXPERIENCES}

During the period 26-30 November I was, for the most part, completely unconscious, unaware of the passage of time, the presence of visitors, the attention of nurses and doctors or my transfer by trolley or ambulance from ward to ward and hospital to hospital. However, within that period there were several brief fluctuations (perhaps $5 \mathrm{~min}$ or so) in degree of awareness, and subsequently I could recall having some human contact and some idea (partly mistaken) about my whereabouts and state of health in these episodes. In the first two episodes I accepted that I was ill in some quite unspecified way and thought that I was to be transferred for operation (unspecified) first to India and then to Australia; in the fourth episode, although much the same in feeling, I thought that I was changing planes on the flight home from Australia.

\section{Recovery}

When I came to on 30 November it was as if waking from sleep. I recognised my wife at once and knew that $I$ was in bed in 
Table I Plasma values ( $\mathrm{mmol} / \mathrm{l})$ before and after transfer to John Radcliffe Hospital and haemofiltration (28 November 1999)

\begin{tabular}{lccccccc}
\hline Date & $\begin{array}{c}\text { Creati- } \\
\text { nine }\end{array}$ & Urea & Potassium & Sodium & Calcium & Phosphate & Albumin \\
\hline August & 333 & & 5.3 & 145 & & & \\
24 November & 345 & & 5.3 & 143 & & & \\
27 November & 559 & & 6.3 & 142 & & & \\
28 November & 545 & 38.4 & 6.5 & 141 & 1.79 & 2.52 & 33 \\
29 November & 189 & 12.4 & 4.3 & 134 & 2.20 & 1.03 & 34 \\
& 324 & 23.4 & 3.9 & 138 & 2.07 & 1.31 & 36 \\
& 236 & 15.5 & 4.2 & 136 & 2.23 & 0.88 & 34 \\
30 November & 306 & 19.2 & 3.8 & 138 & 1.86 & 1.19 & 27 \\
I December & 335 & 24.9 & 3.7 & 138 & 1.88 & 0.79 & 30 \\
2 December & 332 & 27.4 & 3.6 & 135 & 1.91 & 1.25 & 30 \\
21 December & 313 & 21.6 & 3.6 & 137 & 2.02 & 1.05 & 41 \\
\hline Nomat
\end{tabular}

Normal values are: creatinine, 70-120; urea, 7; potassium, 3.5-5.5; sodium, 135-145. Values for August-27 November are from Horton Hospital and those for 28 November-2I December are from the John Radcliffe Hospital. Blood pressure and pulse were: 140/60 and 70 on 27 November; 153/50 and 92 on 28 November; 180/90 and 80 on 2 December. Between 29 November and 2 December there was a slight rise in bilirubin and aspartic transaminase levels but the magnesium level was normal.

hospital somewhere. I felt well, calm and unaware at first that wires of various monitors, an indwelling catheter, oxygen tubes in the nostrils and something in my neck were all attached and restricted movement. I asked where I was and had I just returned from Australia? I had in mind my very recent impressions (sharper in detail and more coherent in recollection than dreams usually are) that I had been to Australia, that our daughter had flown out there to try to see me, but failed, and certain other things had happened, all in a sequence but otherwise timeless.

My wife was easily able to convince me that we were in the John Radcliffe Hospital and that Australia was all a misapprehension. She asked me to repeat back to her things she told me, and although I understood them I could not do this at first. My thoughts seemed immediately to dash off in various random directions and I forgot what I should say. By striving to reply promptly and hold on to the required answer ('attend', 'concentrate') I was, however, soon able to satisfy her. This effort was tiring, and prolonged concentration remained difficult for the next several hours.

\section{Onset}

During recovery I had no recollection of how I had come to the John Radcliffe Hospital, when or what had happened before. After a while I remembered hurting my leg and going to hospital (23 November), but nothing at all after that. With effort, the next day I gradually remembered surgical ward incidents from 24 November and later something from 25 November, the memories rather thin in detail and sparse; for 26 November I could retrieve nothing, yet my wife assures me that I spoke to her that morning about how to operate our video recorder at home.

[Thus there seems to have been some retrograde amnesia, a suggestion of declining awareness of the environment and an impaired registration in memory for at least $24 \mathrm{~h}$ before manifest loss of contact. On re-awakening awareness at first incomplete, there was some failure in registration of short-term memory and an inability to concentrate.]

\section{Episode I}

I come half-awake lying on a vague bed in a very vague room with two young women (in white coats?) standing by my side. I identify them as physiotherapists. One is dark-haired (Indian?) and says nothing; the other is fair, does the talking and laughingly tells me that I need an operation and it will be best for me to transfer to India for it, perhaps to a Christian Mission hospital, possibly called Vellore, with which they have a staff exchange programme (clearly the dark-haired girl). I receive this information passively without curiosity: I do not know or care where I am, or what is wrong with me, although I am prepared to believe I have something requiring treatment and am reassured that it will be well done. I fail to be myself, not very aware of surroundings and with no recollection of any injury or hospitalisation.

Then I gather that the operation in India has been unsuccessful and I am transferred to Australia for a second try. But I have no knowledge of any travel, nursing or medical action.

[I think this must have been a medical interview with duty doctor and nurse on 26 November or possibly 27 November. Obviously I only remember a part of what must have happened and only partially understood what must have been said. Transfer may well have been mentioned, but the idea of India may have been prompted by the (Indian?) nurse and perhaps by an unconscious memory of a fall in India 3 years earlier. About 2 weeks later after recovery I thought I saw these two women passing by elsewhere in the hospital.

Why Australia? On admission to hospital I had been struck by the Australian accents of some of the nurses (and I had read previously in the local paper that Oxford hospitals had imported numbers of Australians to help), although all this was out of the conscious mind. Perhaps an Australian nurse helped me into the ambulance.]

\section{Episode 2}

The Australian operation has failed too and I understand that my daughter is flying out from London to see me. Her ex-husband has offered to help. I am being wheeled away on a trolley, along a corridor, flat on my back and watching the run of the bare pipes in the ceiling, by two staff nurses in uniform. They tell me they are John Radcliffe Hospital nurses, but I know they are lying - I have never been to the John Radcliffe Hospital and I know that this is Australia.

Treatment having failed, they are to dispose of me. We stop by some vague wall machine, which they attach to my left arm and I am given an electric shock there twice, whether to cure or to kill I do not know, but as I expect it is ineffective either way. I begin to believe that they are going to kill me. Apparently a Catholic priest comes frequently to the mortuary to verify that all dead patients have died from natural causes, but the nurses intend to deceive him in my case. They try to put a mask over my 
nose and mouth to give me poison gas and I struggle to stop it, tearing it off when it is half on, with my hand, the mask and the senior nurse's hand twisting against one another. I recall her face and manner very distinctly, outwardly sweet and gentle but with a steely resolve. I have never seen her before. She says "Oh dear, what shall we do?" as she exerts force, and her darkhaired colleague, much vaguer, stands a little apart, pleading with me "Try it for just a little."

As I struggled I felt no emotion, in fact at one point I thought "Why am I doing this? What does it matter if I die?" and I nearly gave up, but then I thought "Why should I let them get away with it (deceiving the priest)?"

[When I recovered, my blood pressure was measured with an electric automatic sphygmomanometer that I had never encountered before. Then, from the cuff inflated on my arm I experienced the squeeze that I recognised was the 'electric shock' I had received earlier. A few days later a strange nurse put her head round the door of my hospital room for a moment and I was astonished to recognise the person I had fought. My wife told me that I had given the staff much trouble by continually pulling off my oxygen mask. When she visited she had helped them by making me keep it on for a while. How could the idea of being killed arise? Did it reflect my earlier feeling of surgical abandonment? A strange squeeze from some automatic machine was interpreted as an electric shock and this perhaps linked in unconscious memory with the shock I had seen in electroconvulsive therapy and in an abattoir; perhaps my transport on the trolley recalled the past unpleasant sight of dead patients wheeled away to the mortuary by porters.]

\section{Episode 3}

I am relaxing somehow, as if on the sidelines of a kind of informal doctors' party, with people moving about socially in several interconnecting rooms all lit with a soft orange light. I am lying across a chair and it is painful in my neck if I try to get up. Two senior nursing sisters, guests at the party, stand together chatting by me. The older, a Yorkshire woman by her accent, offers to get me a cup of tea, and when she returns she says "I took a look at your X-ray and it's quite alright". Both sisters seem, from their conversation, to be in charge of special research units. The younger one has just been appointed to her post and is detailing her plans for developing her unit. I am slightly interested but cannot follow what she says.

[Presumably this corresponds to the 'operation' of inserting a stout intravenous line at the neck, haemofiltration and consequent nursing attention. But nothing is clear and precise; understanding is disjointed and open to doubt.]

\section{Episode 4}

I have moved to the corner of a room in the building with the orange light and sit waiting. I have arrived by air from Australia and am waiting in a transit lounge for the connecting aircraft from London. I am only about halfway home. I think it must be somewhere in South America. The air hostess who has accompanied me comes in and tells me not to worry, but to sit quietly and she will arrange all remaining formalities. She is coming no further but will see me to the next plane.

As I wait alone I hear a slow regular thump-thump-thump outside and think that it is a plane arriving, although the rhythm is a bit slow even for the engine of a propeller-driven aircraft. I elaborate on this thought by imagining the plane I am about to go on as being old and badly maintained by some small, unreliable South American company and liable to crash.

The air hostess returns and we walk out through a side door to another low building. Inside is the check-in desk, this is a table at one end of a long room that is peculiar in having windows along one side that simply look into another larger room where a number of people are going back and forth. The check-in girl, Spanish-Indian, takes my particulars; a vigorous man, a flight engineer, comes in to see if I am fit to fly and then I wait again.

Occasionally the same thumping recurs, getting louder or fainter as the aircraft come and go. I overhear the check-in girl explaining to someone that some of the planes that crash carry passengers who are selected for failing to overcome their illness. I am resigned to being one of the passengers, if this is my fate, but hope that the crash will not be a painful death or prolonged. I also overhear her telling someone about me - my address in Oxfordshire and my blood analyses (I do not take it all in). I am astonished that she knows so much and reveals confidential material. Then she asks me if I am better. I feel that this is to decide whether I am to be put on a crash plane, so I hesitantly admit "No" and then think perhaps I am a little better after all and say "Yes".

[This, in a distorted way, seems to reflect the progress of my nursing care, with staff handovers and some impression of improvements in health leading towards discharge. When I became conscious I found that I was in a single room with side windows just as I saw them at the check-in, my bed against the table with a dark-haired nurse sitting at her station. The thumpthump-thump that I ascribed to aeroplanes was a sound reminiscent of an air-pump that we used to use in the laboratory for freeze-drying specimens in a vacuum. I do not know what the noise really was; perhaps the mental association 'air-pump' led to the conclusion 'aircraft', and so on.]

\section{DISCUSSION}

\section{Validity}

Self-reports, like objective observation, can be flawed by bias and blindness. The credibility of the present subjective report could be increased by reports from similar cases of confusional state in acute renal failure. Confusion arising postoperatively in head injury, hyperparathyroidism and other medical conditions may, of course, have a different pathology from that in kidney disease and, likewise, in confusion syndromes with more and different mental symptoms, so comparisons will require caution (Engel $\&$ Romano, 1959). In the present case many of the experiences follow closely the accounts by Geschwind (1982) and Lishman (1998). The thoughts recorded and related in part to external events would be better connected if there were external observers to test the subject during experience of the psychosis, for the timing of events and partial arousals.

The impairment of understanding disorientation, misidentification of others, development of false beliefs - which is the central disturbance in the confusional state, developed slowly as consciousness declined and was based in memory failure and inattention. I believed that I was living in Australia, presumably because of an overheard voice, and thereafter held to this belief and denied that I could be or ever had been in the John Radcliffe Hospital (in reality, previously I had been both an out-patient and an in-patient). I thought 
that I had been at a doctors' social and checking-in for a flight home. A woman in a white coat was a physiotherapist, not a doctor; the doctor who later inspected my monitors was a flight engineer and the nurse was a check-in girl (Episode 4). These are not absurd answers to the self-posed questions (who, where, what is this?) but near-misses based on brief, limited sensory impression with limited associative memory, a sort of guess without any uncertainty or any correction in relation to previous experience or immediately subsequent events, processes that go on all the time in normal life.

\section{Memory}

In the prodromal phase and in Episodes 3 and 4 speech is heard but no longer understood, except in a very general way. The rhythm is recognised and some of the words, but the meanings that they convey are absent: knowledge available in memory from learning is not tapped but other knowledge (of rhythm, individual words) is used. The sphygmomanometer 'shock' (Episode 2) is interpreted as electroconvulsive therapy and the thoughts of flying (Episode 4) may stem from 'air-pump equals aircraft'. All along (Episodes 1-3) the subject continues to hold his selfidentity, to believe that he is a patient receiving medical treatment and is beginning to recover (Episode 4). The memory store is tapped automatically but inadequately. Associative recall is too brief and narrow, stimulated by only parts of the sensory input (for some relevant discussion of kinds of memory, see Kihlstrom (1983) and Schacter \& Curran (2000)).

\section{Arousal}

Four brief rapid returns of partial consciousness, probably sampling ongoing unconscious mental activity, occurred as a recognised sequence within a state of timelessness - appreciation of time probably depends on registration of events in memory. The returns are unlikely to be random but are responses to perceived 'danger' (in the widest sense) conveyed by situations or words (Episode 1, doctor interview; Episode 2, on a trolley for disposal; Episode 3, operation of haemofiltration; Episode 4, nursing interventions). These arousals serve to show that, even in unconsciousness, auditory and visual stimuli flow in and are a reminder that they can stimulate without conscious perception. As an example, in

\section{CLINICAL IMPLICATIONS}

Self-observation can reveal disturbed mental functions during developing and fluctuating unconsciousness.

Slow development of unconsciousness in renal failure is consistent with a metabolic cause, and interruption by rapid arousal is consistent with a neural cause.

- Nurses applying quick cognitive tests routinely to in-patients might detect early and partial cases.

\section{LIMITATIONS}

Only one case is studied here and self-observation requires external corroboration.

- Cases occurring predominantly in medical and surgical wards require psychologists and psychiatrists for full assessment.

- Cases are easily overlooked if patients are quiet.

J. L. CRAMMER, FRCPsych, Reader Emeritus in Biological Psychiatry, Institute of Psychiatry, De Crespigny Park Denmark Hill, London SE5 8AF, UK

(First received I August 2000, final revision 21 December 2000, accepted 23 December 2000)

blindsight (Zeki, 1993), where there is blindness from destruction of the occipital cortex, the patient's hand movements can be guided by retinal signals.

\section{Mechanism}

The cerebral cortex is the fine analyser responsible for detailed memory registration and for conscious perception, itself dependent on a synthesis of sensations over time and automatic associative recall. Combined perceptions and multiple associations are synthesised further to produce decisions, a conclusion or action. This new brain fine analysis is superimposed on the cruder old (thalamic) brain. The thalamus is a meeting place for sensory inputs and specialised activation or inhibition from the reticular activating symptoms of arousal, which also receive a variety of sensory signals. Thalamus and cortex have multiple links in both directions. Impaired cognition and loss of consciousness follow the progressive but rapidly reversible block of thalamic transmission to cortex, the thalamus continuing to promote actions on its own. In the absence of other mental symptoms (hallucinations, mood disturbance, etc.), this suggests a localised dynamic functional change.

Localised dysfunction implies either an innate particular vulnerability of one part of the central nervous system to a nonspecific agent such as diastolic hypotension (briefly but inadequately observed) or the effect of a specific toxin such as a metabolite in excess. Table 1 shows raised creatinine and urea levels, indicating renal failure, and raised potassium also, but these levels are very unlikely to inhibit nervous activity; the other chemical values also are uninformative. One would need to look for something affecting $\gamma$-aminobutyric acid or $\mathrm{N}$-methyl-D-aspartate glutamate receptors, perhaps, and comparisons with the pharmacological effects of benzodiazepines or changes during anaesthesia with, for instance, nitrous oxide. The slow loss of consciousness in this case of renal failure is consistent with the increase of a biochemical agent.

This neuropathological picture may be wrong. Its value is as a set of challenges, to discover further cases of confusional syndromes, to study them through selfreport and clinical observation, to apply psychometry and biochemical/pharmacological analysis and to test the mechanisms. 
Illumination of the nature of consciousness and on the brain integration underlying psychosis might follow.

\section{ACKNOWLEDGEMENTS}

I am greatly indebted to Professor W. A. Lishman for criticism and encouragement and to Dr P. D. Mason, Consultant Nephrologist, for medical advice and most values in Table I. I thank Dr A. Ellis and Dr P. Taylor and their medical and nursing colleagues at Horton Hospital (NHS) for their diagnostic care and kindly management.

\section{REFERENCES}

Engel, G. L. \& Romano, J. (1959) The syndrome of cerebral insufficiency. Journal of Chronic Diseases, $\mathbf{9}$, 260-277.

Geschwind, N. (1982) Disorders of attention: a frontier in neuropsychology. Philosophical Transactions of the Roya Society of London, Series B, Biological Sciences, 298, 173185

Kapur, N. (1997) Injured Brains of Medical Minds: Views from Within. Oxford: Oxford University Press.

Kihlstrom, J. F. (1993) The psychological unconscious and the self. In CIBA Foundation Symposium 174:
Experimental and Theoretical Studies of Consciousness, pp. 147-167. Chichester: John Wiley \& Sons.

Lipowski, Z. J. (1990) Delirium: Acute Confusional States, pp. 75, 10I-103. New York: Oxford University Press.

Lishman, W. A. (1998) Organic Psychiatry: The Psychological Consequences of Cerebral Disorder (3rd edn), pp. 9, 164, 168-169. Oxford: Blackwell Science.

Mickle, W. J. (190I) Mental wandering. Brain, 24, I-26.

Schacter, D. L. \& Curran, T. (2000) Implicit memory. In The New Cognitive Neurosciences (2nd edn) (ed. M. S. Gazzaniga), pp. 829-840. Cambridge, MA: MIT Press.

Zeki, S. (1993) A Vision of the Brain. Oxford: Blackwell Science. 